\title{
Quantitative ultrasound for the detection and management of osteoporosis
}

\author{
Didier Hans, PhD, PD, (1) Marc-Antoine Krieg, MD, PD.(')
}

\begin{abstract}
Hans D, Krieg MA.
Quantitative ultrasound for the detection and management of osteoporosis.

Salud Publica Mex 2009;5 I suppl I:S25-S37.
\end{abstract}

\author{
Hans D, Krieg MA. \\ Ultrasonido cuantitativo para la detección \\ y manejo de osteoporosis.
}

Salud Publica Mex 2009;5 I supl I:S25-S37.

\begin{abstract}
Quantitative ultrasound (QUS) appears to be developing into an acceptable, low-cost and readily-accessible alternative to dual X-ray absorptiometry (DXA) measurements of bone mineral density (BMD) in the detection and management of osteoporosis. Perhaps the major difficulty with their widespread use is that many different QUS devices exist that differ substantially from each other, in terms of the parameters they measure and the strength of empirical evidence supporting their use. But another problem is that virtually no data exist outside of Caucasian or Asian populations. In general, heel QUS appears to be most tested and most effective. Some, but not all heel QUS devices are effective assessing fracture risk in some, but not all populations, the evidence being strongest for Caucasian females $>55$ years old, though some evidence exists for Asian females $>55$ and for Caucasian and Asian males $>70$. Certain devices may allow to estimate the likelihood of osteoporosis, but very limited evidence exists supporting QUS use during the initiation or monitoring of osteoporosis treatment. Likely, QUS is most effective when combined with an assessment of clinical risk factors (CRF); with DXA reserved for individuals who are not identified as either high or low risk using QUS and CRF. However, monitoring and maintenance of test and instrument accuracy,
\end{abstract}

\section{Resumen}

El ultrasonido cuantitativo (QUS) es una alternativa para la detección y manejo de la osteoporosis de bajo costo y uso práctico, si se compara con las densitometrías de rayos $X$ de doble haz de baja energía (DXA) que determinan densidad mineral ósea (BMD). La mayor dificultad para el uso generalizado del QUS por un lado es que existen muchos instrumentos que son significativamente diferentes uno del otro y por otro en la calidad de la evidencia en que se justifica su empleo, que generalmente es insuficiente y/o poco sistematizada. Otro problema importante del QUS, es que prácticamente no existe información que no sea la generada en poblaciones asiáticas o caucásicas. En general, los estudios de calcáneo realizados con QUS son los más utilizados y mejor validados para evaluar el riesgo de fracturas en algunas poblaciones. La evidencia más grande de su efectividad se conoce para las mujeres caucásicas y asiáticas mayores de 55 años e incluso para los hombres asiáticos mayores de 70 años. Varios instrumentos cuentan con buen sustento científico, que los vuelve confiables para establecer un pronóstico preciso e identificar el riesgo individual de sufrir fracturas por osteoporosis, sin embargo, existe poca evidencia que respalde su uso para iniciar y monitorear el resultado del tratamiento de la osteoporosis. El QUS mejora su efectividad diagnóstica cuando se combina

Part of this work was written in preparation of the 2007 Position Conference Development (chaired by Sandy Baim) of the International Society Clinical Densitometry with the participation of Reinhart Barkmann, Stefano Gonnelli,Alison Stewart, Douglas C. Bauer, Luis Del Rio Barquero, Jonathan J. Kaufman, E. Michael Lewiecki, Roman Lorenc, Paul D. Miller,Wojciech P. Olszynski, Catalina Poiana, Anne-Marie Schott

It does not represent the official position statements of ISCD on the use of QUS in clinical routine. Official position statements issued from the ISCD 2007 Position Conference Development were published in the Journal of Clinical Densitometry early 2008.

(I) Center of Bone Diseases, Lausanne University Hospital, Lausanne, Switzerland.

Received on: February 26, 2008 • Accepted on: March 7, 2008

Address reprint requests to: Dr. Didier Hans, Head of Research and Development, Lausanne University Hospital, Orthopedic Department Center of Bone Diseases, Av. Pierre Decker 4, I0II Lausanne - Switzerland

E-mail:Didier.Hans@chuv.ch 
precision and reproducibility are essential if QUS devices are to be used in clinical practice; and further scientific research in non-Caucasian, non-Asian populations clearly is compulsory to validate this tool for more widespread use.

Key words: Quantitative ultrasound; osteoporosis; fragility fracture; dual-energy X-ray absorptiometry; evidence-based practice con los resultados de un cuestionario que identifica riesgos clínicos. En un escenario ideal, el DXA se debe reservar solo para aquellos individuos que no puedan ser identificados de manera confiable usando QUS y el cuestionario de riesgos clínicos. Si se quiere aceptar a los instrumentos QUS en la práctica clínica, para el monitoreo es indispensable asegurar y mantener la exactitud, precisión y reproducibilidad de los instrumentos y de los técnicos que los utilizan. Se requieren más estudios científicos de poblaciones no caucásicas o asiáticas para validar el uso generalizado del QUS.

Palabras clave: ultrasonido cuantitativo; osteoporosis; fractura por fragilidad; densitometría de rayos $\mathrm{X}$; práctica basada en evidencias
$\mathrm{O}_{\mathrm{b}}^{\mathrm{s}}$ steoporosis is a "disease characterized by low bone mass and micro-architectural deterioration of bone tissue, leading to enhanced bone fragility and a consequent increase in fracture risk". ${ }^{1}$ Hip fractures are especially problematic. In the US, for example, more than 250000 hip fractures occur annually, ${ }^{2-5}$ at least $90 \%$ of which are attributed to osteoporosis; women over 70 years of age are particularly vulnerable. ${ }^{6,7}$ Those who sustain a hip fracture often suffer severe and prolonged physical and social limitations:6,8-13 only $15 \%$ of patients are able to walk without assistance 6 months after the event; $50 \%$ never return to their previous functional state; and roughly $20 \%$ require long-term care. ${ }^{14,15}$ Hip fracture patients also experience a $20 \%$ increase in mortality over the next five years. Even in relatively smaller-population countries like Canada, costs to governments measure in the billions of dollars annually, related both to direct health care costs and insurance. ${ }^{14}$ And, as much of a problem hip fractures currently are, the numbers almost certainly will increase dramatically as an increasing percentage of the population achieves older age, with as many as 6.3 million hip fractures predicted worldwide, annually, by 2050. ${ }^{16}$

Osteoporosis is a major public health concern in Latin America as well, with vertebral osteoporosis affecting $12-18 \%$ and femoral osteoporosis $8-22 \%$ of women 50 years and older. ${ }^{17,18}$ Bone mineral density may be lower in Latin American women over 50 than in their American counter-parts, ${ }^{19}$ with osteopenia affecting almost $60 \%$ of women $\geq 50 .{ }^{18}$ In addition, in Latin America, up to 362 osteoporosis-related hip fractures occur annually per 100000 persons 50 years and older; ${ }^{17}$ vertebral fractures affect almost one in five women over $50 ;{ }^{17,18}$ and between 17 and $37 \%$ of hip fracture sufferers die within a year of their fracture. ${ }^{17}$ The social burden of osteoporosis also is high in South and Central America.
Across 20 Latin American countries, including Mexico, direct costs have ranged from $\$ 4500$ to $\$ 6000$, which is higher than the per capita gross incomes of many Latin American countries, which range from $\$ 410$ to $\$ 7550 .^{17}$

For a variety of reasons that include the huge impact osteoporosis-related fractures have upon individuals and society, increased health expectations among seniors, and recent advances in the prevention and treatment of osteoporosis, the early detection of osteoporosis now is considered essential. Traditionally, measurement of bone mineral density (BMD) via dual-energy x-ray absorptiometry (DXA) has been the means by which osteoporosis is diagnosed and fracture risk estimated ${ }^{20}$ In 1994, the World Health Organization (WHO) published a set of diagnostic criteria to define osteoporosis in postmenopausal Caucasian women, ${ }^{21}$ using BMD values measured by DXA. These criteria express BMD relative to the mean BMD of a healthy young-adult reference population, expressed as a T-score, which represents the number of standard deviations a measured BMD is from the reference population mean. These WHO criteria commonly are applied to BMD measurements at the spine, hip, and forearm, ${ }^{22}$ and define osteoporosis as a T-score of -2.5 or less; in other words, a given individual is said to have osteoporosis if her or his BMD is more than 2.5 standard deviations less than the mean BMD of a healthy, young adult.

Because of the high socio-economic impact of hip fractures and studies which demonstrate that BMD measurements at the proximal femur are most strongly associated with hip fracture, current clinical treatment guidelines for osteoporosis generally are based upon DXA measurements of BMD at the hip -at the femoral neck, for the hip measured in total, or using both measurements. ${ }^{23}$ This being said, a variety of problems exist 
with DXA, which include difficulties extrapolating standards for hip fracture risk to other skeletal sites, like the wrist and lumbar spine. Two other major problems with DXA that are especially pertinent in South and Central America are (1) its cost, and (2) the rarity of DXA instruments in many localities, especially in poorer and/or rural areas and in less developed countries. These two latter problems have led many investigators to search for some lower-cost and more readily-available alternative to DXA for the diagnosis of osteoporosis and / or the estimation of future risk of fragility fractures; and one such alternative that has garnered considerable recent attention has been quantitative ultrasound (QUS).

\section{Quantitative ultrasound: General principles}

Initially used to detect enemy submarines underwater during World War II, ultrasonic waves are sound waves outside the threshold of human hearing, which pass easily through fluid and other tissues, and which are altered upon contact with bone, in terms of their shape, intensity and speed. Over the years, ultrasonic (US) devices have found a diverse array of clinical applications in medicine, including uses in cardiology to assess cardiac size and function and vascular flow, obstetrics to assess fetal development, general medicine to examine for intra-abdominal and intra-peritoneal masses, and rheumatolology and orthopedics to both diagnose and treat conditions like bursitis and tendonitis. As opposed to qualitative ultrasound, which just generates pictures, quantitative ultrasound uses ultrasonic waves at lower frequencies to generate empirical measurements.

With respect to the detection of osteoporosis, QUS can be used to measure a variety of parameters that pertain to bone density, parameters that are related to the velocity and attenuation of US waves as they pass through bone. Advantages of QUS over DXA are that it is inexpensive, transportable, and ionizing radiation free. The low cost and transportability could make QUS an especially valuable osteoporosis detection tool wherever cost or instrument inaccessibility renders DXA difficult or impossible. But does QUS work? Already, there is evidence that QUS is as effective as axial DXA in predicting hip fractures and all osteoporosis-related fractures in elderly women. ${ }^{24-26}$ Having said this, numerous potential problems still exist with the use of QUS for osteoporosis detection. For example, care must be exercised interpreting US velocity and attenuation, as they are calculated differently depending upon the manufacturer and model of the ultrasound device. Similarly, there are significant differences between QUS instruments from different manufacturers, differences that affect the interpretation of results and limit comparisons between devices.

\section{Different QUS devices}

QUS devices can be classified into three types, related to the form of US transmission used:

1. Trabecular sound transmission is the most commonly utilized category of devices, for which the most evidence exists supporting its use. It is best utilized measuring the heel..$^{24,25}$

2. Cortical transverse transmission currently only is used in phalanx contact devices, ${ }^{27}$ to date, little evidence supports the use of these devices clinically for osteoporosis.

3. Cortical axial transmission presently is being investigated for use in phalanges, the radius and the tibia; ${ }^{27}$ no clinical application have been proven, to date.

As just noted, heel devices currently appear to have the most clinical applications, with some devices -like the GE-Lunar Achilles and the Hologic Sahara- better tested and more proven effective than others (table I). For these purposes, the recommended parameter of interest generally has been the heel stiffness index (SI) or the Quantitative index (QUI), which is a composite score combining the results of broadband ultrasound attenuation (BUA) and speed of sound (SOS), as measured in meters per second.

The remainder of this paper will review the clinical use of QUS in the following settings: 1) the prediction of fracture risk; 2) the diagnosis of osteoporosis; 3 ) the initiation of osteoporosis treatment or prevention; 4) the monitoring of such treatment; and 5) osteoporosis case finding. The paper will conclude by examining 6) quality assurance and quality control issues pertaining to the clinical application of QUS.

\section{1) Using QUS to predict fracture risk}

At the present time, there is satisfactory (cross-sectional and/or prospective) evidence that QUS can be used to assess fracture risk in some, but not all populations, as defined by sex, age and ethnic background. ${ }^{28-96}$ This is particularly true of heel QUS and for hip versus spinal fractures. Having said this, because of various methodological issues, it is difficult to compare studies. Nonetheless, combining the results from 13 studies involving 9561 patients, ${ }^{33,39,40,43-45,48,52,58-60,69,79}$ it is reasonable to state that the increase in relative risk observed for each standard deviation decrease in stiffness index (SI), 
Table I

Quantitative Ultrasound (QUS) Devices Currently Available

\begin{tabular}{|c|c|c|c|c|}
\hline Manufacturer & Model & $\begin{array}{l}\text { Ability to assess } \\
\text { hip fracture risk }\end{array}$ & $\begin{array}{l}\text { Ability to assess } \\
\text { spine fracture risk }\end{array}$ & $\begin{array}{l}\text { Ability to assess } \\
\text { all fracture risk }\end{array}$ \\
\hline GE-medical (Lunar) & Achilles & Proven in most populations & Proven in most populations & Proven in most populations \\
\hline DMS & Ubis $3000 / 5000$ & Some evidence & Some evidence & Some evidence \\
\hline Hologic & Sahara & Proven in Caucasians & Proven in Caucasian females & Proven in Caucasians \\
\hline Norland (McCue) & Cuba Clinical & Proven in Caucasians & Some evidence & Proven in Caucasians \\
\hline IGEA & DBM Sonic BP & Proven in Caucasian females & Proven in Caucasian females & Some evidence \\
\hline BeamMed (Sunlight) & Omnisense & Some evidence & Some evidence & Some evidence \\
\hline Meditech & DTU-One & No evidence & Some evidence & Some evidence \\
\hline Aloka & AOS- 100 & Some evidence & No evidence & No evidence \\
\hline Medilink & Osteospace & & & \\
\hline Quidel Inc. & QUS-2 & & & \\
\hline Ishikawa Seisakusho Ltd. & Benus & & & \\
\hline Elk Co. & CM- $100 / 200$ & & No Evidence & \\
\hline Osteosys Co. & Sonost $2000 / 3000$ & & & \\
\hline BMtech2I Co. & Osteolmager Plus & & & \\
\hline BMtech2I Co. & Osteo Pro & & & \\
\hline
\end{tabular}

Data gleaned from Quantitative Ultrasound (QUS) in the Management of Osteoporosis:The 2007 ISCD Official Positions

measured at the heel using QUS, is roughly 2.0 for the hip and spine, and approximately 1.5 for all fractures combined. Consequently, heel QUS is much the same as DXA BMD, in terms of hip and spine fracture risk per standard deviation decrease. ${ }^{97,98}$

Although some differences may exist in the expression of osteoporosis and overall fracture risk in Hispanics versus general Caucasians and other ethnic populations, ${ }^{99,100}$ there is ample empirical evidence that the heel QUS stiffness index, using some but not all QUS devices, is predictive of hip fracture risk in Caucasian and Asian women over age 55, and of any fracture risk in Caucasian women > 55 (table II). Weaker evidence exists that the heel QUS stiffness index, again using some but not all QUS devices, is predictive of hip fracture risk in Caucasian and Asian men over age 70; of vertebral fracture risk in Caucasian and Asian women over age 55; and of any fracture risk in Asian women and Caucasian or Asian men $>70$. With respect to QUS devices from one of the other two categories, phalanx QUS devices utilizing cortical transverse transmission might predict non-vertebral fracture risk in Caucasian women $>70$; however, to date, cortical axial transmission devices have no proven clinical application.

Another practical question is: which QUS device is best to use? As indicated in table I, the GE Lunar Achilles and the Hologic Sahara are among the best tested devices, at the hip, spine and overall, and both seem effective for most females; the former may be preferable in males. Some evidence exists supporting the use of the Norland Cuba Clinical and the IGEA DBM Sonic BP, at least among Caucasians. However general results on the IGEA DBM Sonic device are not very impressive. Consequently, the three heel devices appear to be the most reasonable to use, at this time, though further testing of these and other devices clearly is necessary.

\section{2) Using QUS to diagnose osteoporosis}

Diagnosing osteoporosis using QUS is less supported by evidence and more complicated and problematic than assessing fracture risk is. To start with, the T-score diagnostic criteria of -2.5 , classically used for DXA BMD, cannot be applied to QUS without discrepancies in the numbers of women diagnosed with osteoporosis. This is because there are tremendous variations in QUS measurements by skeletal site, and because different QUS devices yield different results. If, for example, the prevalence of osteoporosis is defined as -2.5 standard deviations from the mean threshold for QUS, even within the same sample population, different QUS instruments and different skeletal sites generate prevalence estimates that vary as much as ten-fold; for example, prevalence estimates among Caucasian women $>65$ have ranged 
Table II

Using Quantitative Ultrasound (QUS) TO ASSESS FRACTURE RISK

\begin{tabular}{llll} 
Device & $\begin{array}{c}\text { Population } \\
\text { studied }\end{array}$ & $\begin{array}{c}\text { Skeletal } \\
\text { site studied }\end{array}$ & $\begin{array}{c}\text { Strength } \\
\text { of evidence }\end{array}$ \\
Some, but not all heel QUS devices & CF $>55$ y/o & Hip & Good \\
\hline Some, but not all heel QUS devices & AF $>55$ y/o & Hip & Fair \\
\hline Some, but not all heel QUS devices & $\mathrm{CM}>70$ y/o & Hip & Fair \\
\hline Some, but not all heel QUS devices & AM $>70$ y/o & Hip & Fair \\
\hline Some, but not all heel QUS devices & CF $>55$ y/o & Spine & Good \\
\hline Some, but not all heel QUS devices & AF $>55$ y/o & Spine & Poor \\
\hline Some, but not all heel QUS devices & CF $>55$ y/o & Overall & Good \\
\hline Some, but not all heel QUS devices & AF $>55$ y/o & Overall & Fair \\
\hline Some, but not all heel QUS devices & CM $>70$ y/o & Overall & Fair \\
\hline Some, but not all heel QUS devices & AM $>70$ y/o & Overall & Fair \\
\hline Phalanx cortical transverse & & & \\
transmission devices & CF $>70$ y/o & Non-vertebral & Fair \\
CF= Caucasian females; AF= Asian females; CM $=$ & Caucasian males; AM= \\
Asian males & &
\end{tabular}

from 4 to $50 \% .{ }^{96,101-105}$ To overcome this dilemma, there is a need for pre-defined, device-specific diagnostic thresholds. One recommended system suggests calibrating QUS measurements with DXA results, the latter used as the 'gold standard', so that an upper QUS threshold is set to identify osteoporosis with $90 \%$ sensitivity, and a lower threshold is set to identify osteoporosis with $90 \%$ specificity. ${ }^{106,107}$ A similar approach already has been recommended by the UK National Osteoporosis Society to define upper and lower thresholds for $\mathrm{pDXA}, 108,109$ the results of which are highly correlated with QUS. Using such a system, one could identify osteoporosis with high probability in patients whose results fall below the lower threshold for QUS, where specificity exceeds $90 \%$; between the upper and lower thresholds, the diagnosis of osteoporosis would be considered quite equivocal, so that another means of measurement, like DXA BMD, would be highly recommended; and above the upper threshold for QUS, where the sensitivity of a value below the threshold is $90 \%$, osteoporosis would be deemed unlikely.

We, in fact, utilized this approach in 5954 women 75 years and older who took part in the EPIDOS Study, utilizing the $90 \%$ sensitivity threshold for the Achilles stiffness index of SI $=78 \%$, and the $90 \%$ specificity threshold of SI=57\%. Using these cut-off points generated $11 \%$ false positive (FP) and $13 \%$ false negative (FN) results, which are comparable to the FP and FN rates of many other tests. Based upon these results, we believe that device-specific heel QUS thresholds for $90 \%$ sensitivity and $90 \%$ specificity in specific populations defined by sex, age, and ethnic background, can be used to identify individuals who have either a high or a low likelihood of osteoporosis, even though only limited evidence exists supporting the use of any existing QUS device for this purpose. Devices that have been evaluated include the GE-Lunar Achilles, the Hologic Sahara, and the DMS UBIS-5000, each of which uses a different measure and different upper and lower likelihood thresholds, as indicated in table III. What can be concluded is that, regardless of the QUS device used, values that fall between the upper and lower thresholds strongly warrant further evaluation using DXA BMD as a more definitive test.

\section{3) Using QUS to initiate osteoporosis treatment}

Except in patients with a low-energy fracture of the hip or spine, when the fracture alone is adequate to require treatment, all currently-published guidelines or recommendations for the initiation of osteoporosis treatment are based upon DXABMD values; in no instance, to date, are the results of QUS the definitive parameter. Despite this, several studies have demonstrated high levels of correlation $(r \sim 0.90)$ between heel trabecular sound transmission and BMD at matched skeletal sites. ${ }^{110-113}$ Moreover, both SOS and BUA, standard QUS measurements, are dependent upon overall bone strength which, in turn, is related to bone density, architecture and turnover, and the extent of bone mineralization. .10,112,114-121 These factors likely work together to maintain overall bone quality and strength, and to prevent fractures and other bone failure. ${ }^{110,112,114-121}$ QUS parameters related to heel trabecular transverse transmission are highly correlated with bone strength. ${ }^{117,122-129}$ Consequently, it is conceivable that guidelines could be created using QUS to guide when to initiate osteoporosis treatment,

\section{Table III}

\section{Using Quantitative Ultrasound (QUS) to diagnose OSTEOPOROSIS}

\begin{tabular}{lccc} 
Device & $\begin{array}{c}\text { Population } \\
\text { studied }\end{array}$ & $\begin{array}{c}\text { Threshold for } \\
\text { high likelihood } \\
\text { of osteoporosis }\end{array}$ & $\begin{array}{c}\text { Threshold for } \\
\text { low likelihood } \\
\text { of osteoporosis }\end{array}$ \\
GE-Lunar Achilles & CF and AF $>65$ & $\mathrm{SI} \leq 57.0$ & $\mathrm{SI}>78$ \\
\hline Hologic Sahara & $\mathrm{CF}$ and AF $>65$ & $\mathrm{QUI} \leq 59.0$ & $\mathrm{QUI}>83$ \\
\hline DMS UBIS-5000 & $\mathrm{CF}$ and AF $>65$ & $\mathrm{BUA} \leq 55.0$ & $\mathrm{BUA}>62$ \\
CF= Caucasian females; AF $=$ Asian females &
\end{tabular}


especially if combined with the use of clinical risk factors. ${ }^{130}$ To date, however, no randomized clinical trails have been published examining whether individuals identified as high risk for fracture by QUS respond to treatment.

At the present time, published evidence does not support using QUS device-specific values to initiate osteoporosis treatment in women younger than 65 years or in men of any age, but some evidence exists supporting QUS use in other populations, when DXA is not available. These populations include 1) Caucasian and 2) Asian women who are between the ages of 65 and 74 years, exhibit results below the lower specific device threshold (i.e. SI $\leq 57.0$ with the GE-Lunar Achilles device), and have at least two clinical risk factors (table IV); and 3) Caucasian and 4) Asian women who are 75 years or older, exhibit results below the lower specific device threshold (i.e. SI $\leq 57.0$ with the GE-Lunar Achilles device), and have at least one clinical risk factor besides age. Table IV lists pertinent clinical risk factors that we have identified by examining published meta-analyses, as well as literature reviews written by Kanis ${ }^{131}$ and Durosier. $^{98}$

Currently, a World Health Organization (WHO) task force is developing a model to predict the 10-year probability of osteoporosis-related fractures, combining femoral neck DXA BMD measurements and CRF. This also could be done combining QUS and CRF, using a device-specific T-score. QUS-generated high and low risk probabilities -for example, $\mathrm{SI} \leq 57.0$ and $>78$, respectively, for the GE-Lunar Achilles device- then could be used to decide whether treatment is warranted. Because different devices have their own high-and low-probability threshold values that all correspond to roughly the same two levels of fracture risk, this approach could be

\section{Table IV}

Clinical Risk factors for OSteoporosis FOR USE WITH QUANTITATIVE ULTRASOUND

\begin{tabular}{l} 
- Age over 75 years $^{132,133}$ \\
\hline - Low BMI $\left(<20 \mathrm{~kg} / \mathrm{m}^{2}\right)^{132,134,135}$ \\
\hline Previous fragility fracture after the age of $50^{132,135,136}$ \\
\hline - Maternal history of hip fracture ${ }^{137}$ \\
\hline - Current smoking \\
\hline - Diabetes \\
\hline - No prior hormone replacement therapy (HRT) \\
\hline - Fall within the past 12 months ${ }^{135,140}$ \\
\hline - Use of arms to stand up 3 times from a chair (Missed Chair Test)
\end{tabular}

utilized independently of the measurement instrument used. Preliminary results demonstrating the benefits of this combined CRF plus technology approach already have been published by Hans et al. ${ }^{142}$

Unfortunately, whereas QUS and BMD are highly correlated in trabecular bone ${ }^{143}$ and this correlation reasonably well understood, the situation is considerably more complex with cortical measurements. Many properties influence these measurements, including cortical thickness, mineralization, porosity and lamellar structure, and it is not clear to what degree these various properties contribute to bone strength. ${ }^{144-147}$ Consequently, QUS devices that measure cortical bone, like the cortical transverse transmission devices currently used to assess phalanges, and the cortical axial transmission devices being investigated for use with phalanges, the radius and tibia, cannot be recommended as tools to determine the appropriateness of initiating osteoporosis treatment at this time.

\section{4) Using QUS to monitor osteoporosis treatment}

At this time, QUS cannot be recommended for the monitoring of treatment response in patients with osteoporosis, both due to the absence of large-scale, randomized, double-blinded and placebo-controlled clinical trials (RCT) and the relatively equivocal evidence that has been generated by the studies that have been published. ${ }^{148-164}$ It has been observed that changes in heel QUS parameters, especially the stiffness index (SI), do mimic the treatment response observed in BMD. In two studies involving alendronate, for example, the Achilles SI was observed to significantly increase with treatment over time. ${ }^{149,150}$ Clearly, however, further RCT are needed to determine if QUS parameters are sensitive enough to change with treatment, if the various QUS instruments are sensitive enough to detect these changes, and if the precision of these instruments is such that repeated measures can be performed without excessive 'noise'. There is some evidence that instrument precision is adequate in the short-term; but what about over a longer period of time? What can be said is that, if QUS is going to be used to monitor treatment, likely the heel devices will be most successful, since trabecular measurements appear to be more accurate than those that have been achieved with any of the cortical devices.

\section{5) Case finding}

Case finding involves distinguishing subjects at highest or lowest risk for a given disorder, who hence do not require further investigation because their disease 
status is reasonably well known, from subjects at intermediate risk whose disease status remains equivocal, thereby requiring further evaluation. At present, there is fair empirical support for the use of heel QUS for osteoporosis case finding among Caucasian and Asian females who are at least 65 years old. The evidence for the use of cortical devices is poor, and for males and other ethnic populations generally lacking altogether. Nonetheless, we feel that the proposed case-finding protocol depicted in figure 1 is reasonable for clinical practice, in terms of distinguishing individuals who require from those who do not require further evaluation of fragility fracture risk.
To begin, each patient would undergo an assessment to identify any clinical risk factors. Using this protocol, patients who are suspected to be at risk for secondary osteoporosis-for example, because of prolonged systemic use of corticosteroids- or who have a clinicallyevident vertebral fracture would proceed directly to management deemed appropriate for their condition. All others would undergo a heel QUS. Based upon this, those whose QUS parameters suggest a low likelihood of future fracture would be assigned to receive primary prevention, unless they have had a fragility fracture, in which case they would undergo DXA BMD. Those for whom results indicate an intermediate risk of future

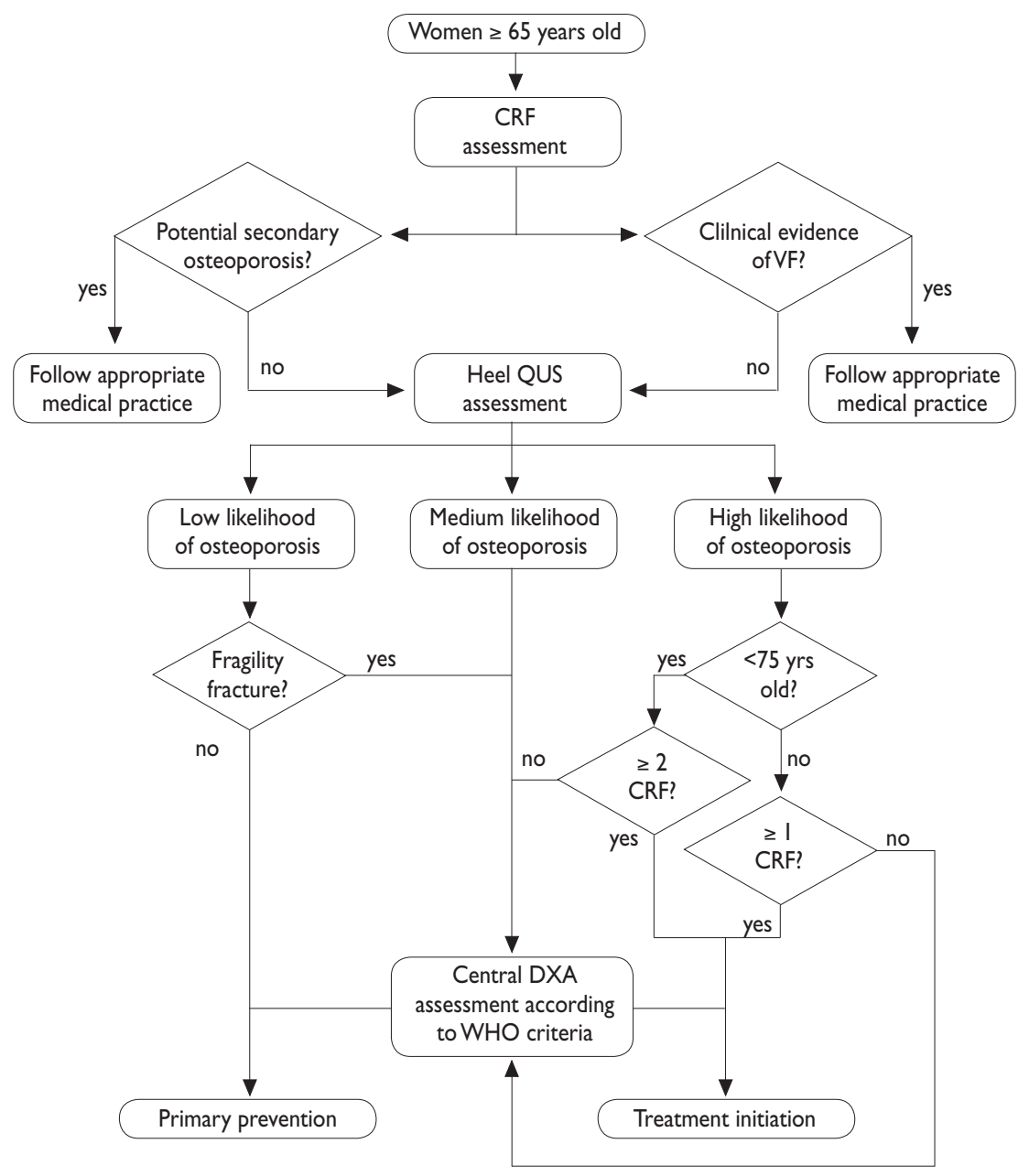

$\mathrm{CRF}=$ clinical risk factors; $\mathrm{VF}=$ vertebral fracture; $\mathrm{QUS}=$ quantitative ultrasound;

$D X A=$ dual-energy $\mathrm{x}$-ray absorptiometry; $\mathrm{WHO}=$ World Health Organization

Figure I. Case-Finding protocol 
fracture, in that they lie between the upper and lower thresholds, also would undergo DXA BMD. And those patients for whom the risk of future fracture is deemed to be high, based upon the results of heel QUS, would proceed to treatment if they are $\geq 75$ years old and have at least one other CRF besides age, or if they are $<75$ and have at least two clinical risk factors. Otherwise, they too would proceed to DXA BMD.

The primary advantage of this protocol, especially in terms of cost, is that it saves performing costly and, sometimes relatively inaccessible DXA on all patients. In particular, those with a low risk of fracture by QUS would avoid DXA unless they have had a fragility fracture; and those with a high risk of fracture by QUS would avoid DXA if they have at least two CRF, counting age. As stated at the outset, this would have particular relevance in localities in which access to DXA is scarce or too costly to be performed, both of which likely apply to the majority of patients in many developing countries.

\section{6) QUS quality assurance and quality control}

Technically, quality assurance primarily deals with the performance of the equipment, whereas quality control is more heavily grounded in theory and statistics, emphasizing the quality of the actual test. For practical purposes, however, these two concepts often are treated as the same, ${ }^{165}$ and this paper will not seek to further delineate them. The primary issues of importance are those of test/equipment accuracy, precision, and reproducibility. Accuracy is a measure of how close a provided answer or value is to the true answer or value. ${ }^{166}$ If one were to visualize a game of darts, for example, darts that hit the bull's eye are said to be accurate. Precision, on the other hand, is a measure of consistency. If five darts are thrown, do they all end up close to each other (high precision) or widely spread (low precision)? ${ }^{166}$ The two concepts, accuracy and precision, are not the same. One could have all one's darts bunched together far from the bull's eye (high precision, low accuracy); or one could have all one's darts widely spread, but all equidistant from the bull's eye, so that the average of their positions is near to the center dot (high accuracy, low precision). Reproducibility measures how well the same test done on the same person or sample yields the same result, whether the test is performed by the same technician (intra-observer) or a different technician (inter-observer). ${ }^{166}$ These three parameters are important, whether a test is being performed to diagnose disease, monitor its course, or identify potential cases.

With heel QUS, there are several potential sources of in vivo measurement error, which include surround- ing soft tissue and foot positioning; ${ }^{167-170}$ soft-tissue thickness, ${ }^{171-173}$ temperature ${ }^{170,174}$ and composition; the quality of sound transmission from the coupling medium to the skin; and properties of the coupling medium between the transducers and the skin, whether it be a fluid bath or sound transmitting pads. ${ }^{167,170,175-178}$ One of the most important components of QA entails using some sort of test object, which can be either a standard or phantom, ${ }^{165}$ to monitor instrument performance and make necessary calibrations when measurement accuracy begins to stray. A standard is an object of known acoustic properties, which does not necessarily resemble the anatomy of interest. Conversely, a phantom is designed to emulate the anatomy and acoustic properties that exist during in vivo measurements as much as possible. With respect to optimizing QUS device performance, phantoms are more useful. Unfortunately, no universally-applicable phantoms exist. Consequently, manufacturer-specific phantoms must be used, and measured each day that the respective device is used, following the manufacturer's protocol, to detect performance changes that may result from component aging or failure. Detection of these changes allows both for necessary repairs, and for adjustments to specific readings by applying a correction factor to patient data. ${ }^{177}$ Table $\mathrm{V}$ provides a brief list of important guidelines regarding quality assurance and control:

\section{Summary}

To date, no satisfactory evidence exists either supporting or refuting the usefulness of quantitative ultrasound in Latin populations, so that further research clearly is warranted. Nonetheless, there is enough evidence in other populations to suggest that QUS may be an acceptable, low-cost and readily-accessible alternative to DXA measurements of BMD in the management of osteoporosis in Hispanics. Many different QUS devices exist that are quite different in terms of the parameters they measure and the strength of empirical evidence supporting their use. In general, heel QUS appears to be most tested and most effective. Some, but not all heel QUS devices are effective assessing fracture risk in some, but not all populations, the evidence being strongest for Caucasian females $>55$ years old, though some evidence exists for Asian females $>55$ and for Caucasian and Asian males $>70$. Certain devices may allow for the accurate diagnosis of osteoporosis, but very limited evidence exists supporting the use of QUS use during the initiation or monitoring of osteoporosis treatment. A reasonable protocol for osteoporosis case-finding relies upon the combined assessment of clinical risk factors and heel QUS. However, monitoring and maintenance of test and 


\section{Table V \\ ReCOMMENDATIONS FOR QUALITY ASSURANCE/QUALITY CONTROL IN QUS SYSTEMS}

(I) QUS-specific information and training must be provided prior to measuring patients in routine clinical practice;

(2) To assist in optimizing QUS measurements, in vivo precision error should be calculated by each QUS facility's technologist, in accordance with ISCD recommendations for DXA, rather than relying upon precision values reported in the literature or by the manufacturer; once measurement precision is known, it is possible to determine the minimal detectable difference between two measurements that is statistically significant;

(3) Obtaining facility accreditation for QUS is recommended;

(4) As with other methods, with QUS, anatomically-consistent regions of the bone must be measured to enhance accuracy, and precision is affected by the quality of sequential repositioning of each patient; the use of an imaging system may help to overcome positioning errors by placing a region of interest (ROI) on the image; ${ }^{179}$

(5) Attempts should be made to maintain a relatively-constant and standard temperature for all readings; and when an aberration is felt to exist because of temperature, accommodation should be made and the measurement repeated; for example, with heel measurements, a cold foot can falsely lower SOS measurements; hence, if the SOS result is low and this value clinically-important, the foot should be warmed and the measurement repeated;

(6) Oedema of the foot can significantly affect heel QUS readings, so that this test should not be performed in such patients;

(7) Achieving good-quality coupling of the ultrasonic beam as it passes into the body is essential; a coupling gel or liquid must be used with all methods to ensure proper penetration through the skin;

(8) Manufacturer-specific phantoms must be measured each day a device is used, following the manufacturer's protocol, to detect equipment changes that may result from component aging or failure, and thereby allow for necessary repairs, or for adjustments to specific readings by applying a correction factor to patient data; ${ }^{177}$

(9) It generally is accepted that long-term stability and precision errors detected during phantom measurement should not exceed $1 / 4$ T-score to restrict misclassification errors to within a clinically-acceptable level $\left.\right|^{119}$

(10) Each facility should periodically assess the performance of its technologists; two essential components of this are $(I)$ ensuring that adequate time is utilized performing measurements; and (2) measuring intraobserver reliability to generate a coefficient of variation (CV); the in vivo $\mathrm{CV}$ s generally quoted in the literature range from $0.8-5 \%$ and 0.2 - $1 \%$ for BUA and SOS, respectively.

instrument accuracy, precision and reproducibility are paramount to the effective clinical use of QUS. And, as stated earlier, there is a huge call for further research in non-Caucasian, non-Asian populations.

\section{References}

I. Anonymous. Consensus development conference: diagnosis, prophylaxis and treatment of osteoporosis. Am J Med 1993;94:646-650.

2. Riggs, BLaM, LJ, 3rd, Medical progress series: Involutional osteoporosis: N Engl J Med 1986;314:1676-1686.

3. Riggs BL, LJ Melton, 3rd. The worldwide problem of osteoporosis: insights afforded by epidemiology. Bone 1995; 17(5 suppl):505S-5I IS.
4. Kelsey JL, Hoffman S. Risk factors for hip fracture. N Engl J Med 1987;316(7):404-406.

5. Statistics NCfH.Advance data from vital and health statistics: 1985 summary: national hospital discharge survey. 1986, US Public Health Service (PHS): Hyattsville. p. PHS 86-1250.

6. Cummings SR, et al. Epidemiology of osteoporosis and osteoporotic fractures. Epidemiol Rev 1985;7:178-208.

7. Melton LJ, 3rd, Riggs BL, Epidemiology of age-related fractures, in The osteoporotic syndrome: detection, prevention, and treatment. Grune \& Stratton: New York, 1987:45-72.

8. Baudoin C. [Fractures of the proximal femur. Epidemiology and economic impact]. Presse Med 1997;26(3): I45I- 1456.

9. Melton LJ, 3rd. Epidemiology of hip fractures: implications of the exponential increase with age. Bone 1996; I8(3 suppl): I2IS- I25S.

10. Fisher ES, et al. Hip fracture incidence and mortality in New England. Epidemiology 1991;2(2): I 16-122.

II. Sernbo I, Johnell O. Consequences of a hip fracture: a prospective study over I year. Osteoporosis Int 1993;3(3): I 48-I53.

12. Wolinsky FD, Fitzgerald JF, Stump TE. The effect of hip fracture on mortality, hospitalization, and functional status: a prospective study.Am J Public Health 1997;87(3):398-403.

13. Cummings SR, Rubin SM, Black D. The future of hip fractures in the United States. Numbers, costs, and potential effects of postmenopausal estrogen. Clin Orthop 1990(252): 163-166.

I4. Brown J, Josse R. Clinical practices guidelines for the diagnosis and management of osteoporosis in Canada. CMAJ 2002;167(I0):SI-S34. 15. Magnusson $\mathrm{H}$, et al. Bone mass changes in weight-loaded and unloaded skeletal regions following a fracture of the hip. Calcif Tiss Int 200I;69(2):78-83.

16. Kiebzak GM, et al. Undertreatment of osteoporosis in men with hip fracture Arch Int Med 2002;162(19):2217-2222.

17. Morales-Torres J, Gutiérrez-Ureña S, O.C.o.P.-A.L.o.A.f. Rheumatology, The burden of osteoporosis in Latin America. Osteoporos Int 2004; 15(8):625-632.

18. Murrillo-Uribe A, et al. [Osteoporosis in Mexican postmenopausal women. Magnitude of the problem. Multicenter study] [Article in Spanish]. Ginecol Obstet Mex 1999;67:227-233.

19. Beyene Y, Martin MC. Menopausal experiences and bone density of Mayan women in Yucatan, Mexico.Am J Hum Biol 200 I; I3(4):505-5I I. 20. Kanis JA, et al. Guidelines for diagnosis and management of osteoporosis. The European Foundation for Osteoporosis and Bone Disease. Osteoporos Int 1997; 7(4):390-406.

21.WHO,Assessment of fracture risk and its application to screening for postmenopausal osteoporosis. Geneva,World Health Organization, 1994. 22. Hans D, et al. Skeletal sites for osteoporosis diagnosis: the 2005 ISCD Official Positions.J Clin Densitom 2006;9(I):15-2I.

23. Kanis JA, Gluer CC. An update on the diagnosis and assessment of osteoporosis with densitometry. Committee of Scientific Advisors, International Osteoporosis Foundation. Osteoporos Int 2000; I I(3): 192-202.

24. Njeh CF, Black DM. Calcaneal quantitative ultrasound:Water-coupled in: Quantitative Ultrasound:Assessment of Osteoporosis and Bone Status, ed. Njeh CF, Hans D, Fuerst T, Gluer CC, Genant HK. 1999, London, UK: Martin Dunitz: 109-124.

25. Cheng S, Hans D, Genant HK. Calcaneal quantitative ultrasound: Gel-coupled in: Quantitative Ultrasound:Assessment of Osteoporosis and Bone Status, ed. C.F. Njeh, Hans, D., Fuerst, T., Gluer, C.C., Genant, H.K. 1999, London, UK: Martin Dunitz: I25- I 44.

26. Marin F, et al. Relationship between bone quantitative ultrasound and fractures: a meta-analysis. J Bone Miner Res 2006;2 I (7): I I 26- I I 35.

27. Hans D, Fan B, Fuerst T. Non-heel quantitative ultrasound devices. in: Quantitative Ultrasound:Assessment of Osteoporosis and Bone Status, ed. Njeh CF, Hans D, Fuerst T, Gluer CC. Genant, H.K. 1999, London, UK: Martin Dunitz: 145-162. 
28. Alenfeld FE, et al. Ultrasound measurements at the proximal phalanges in healthy women and patients with hip fractures. Osteoporos Int 1998;8(5):393-398.

29. Augat, P., et al.,Assessment of bone mineral at appendicular sites in females with fractures of the proximal femur. Bone 1998;22(4):395-402. 30. Barkmann $R$, et al.A new method for quantitative ultrasound measurements at multiple skeletal sites: first results of precision and fracture discrimination.J Clin Densitom 2000;3(I):I-7.

3I. Bauer DC, et al. Quantitative ultrasound and vertebral fracture in postmenopausal women. Fracture Intervention Trial Research Group.J Bone Miner Res 1995; 10(3):353-358.

32. Cepollaro $\mathrm{C}$, et al.The combined use of ultrasound and densitometry in the prediction of vertebral fracture. Br J Radiol 1997;70(835):69I-696. 33. Clowes JA, Eastell R, Peel NF. The discriminative ability of peripheral and axial bone measurements to identify proximal femoral, vertebral, distal forearm and proximal humeral fractures: a case control study. Osteoporos Int 2005; 16(I2): I794-I802.

34. Damilakis J, et al. Discrimination of hip fractures by quantitative ultrasound of the phalanges and the calcaneus and dual X-ray absorptiometry. Eur J Radiol 2004;50(3):268-272.

35. Damilakis J, et al. Ultrasound velocity through the cortex of phalanges, radius, and tibia in normal and osteoporotic postmenopausal women using a new multisite quantitative ultrasound device. Invest Radiol 2003;38(4):207-2II.

36. Donaldson MM, et al. Calcaneal ultrasound attenuation in an elderly population: measurement position and relationships with body size and past fractures. Osteoporos Int 1999;10(4):316-324.

37. Drozdzowska B, Pluskiewicz W. The ability of quantitative ultrasound at the calcaneus to identify postmenopausal women with different types of nontraumatic fractures. Ultrasound Med Biol 2002;28(II-I2): 149I-I497. 38. Drozdzowska B, Pluskiewicz W, F. de Terlizzi. The usefulness of quantitative ultrasound at the hand phalanges in the detection of the different types of nontraumatic fractures. Ultrasound Med Biol 2003;29(II):1545-1550.

39. Ekman A, et al. Dual X-ray absorptiometry of hip, heel ultrasound, and densitometry of fingers can discriminate male patients with hip fracture from control subjects: a comparison of four different methods. J Clin Densitom 2002;5(I):79-85.

40. Ekman A, et al. DXA of the hip and heel ultrasound but not densitometry of the fingers can discriminate female hip fracture patients from controls: a comparison between four different methods. Osteoporos Int 2001;12(3): 185-191.

4I. Frediani B, et al. Calcaneus ultrasonometry and dual-energy X-ray absorptiometry for the evaluation of vertebral fracture risk. Calcif Tissue Int 2006;79(4):223-229.

42. Frost ML, Blake GM, Fogelman I.A comparison of fracture discrimination using calcaneal quantitative ultrasound and dual X-ray absorptiometry in women with a history of fracture at sites other than the spine and hip. Calcif Tissue Int 2002;7I(3):207-2II.

43. Frost ML, Blake GM, Fogelman I. Does the combination of quantitative ultrasound and dual-energy X-ray absorptiometry improve fracture discrimination? Osteoporos Int 200I;12(6):47I-477.

44. Frost ML, Blake GM, Fogelman I. Does quantitative ultrasound imaging enhance precision and discrimination? Osteoporos Int 2000; I (5):425-433. 45. Frost ML, Blake GM, Fogelman I. Contact quantitative ultrasound: an evaluation of precision, fracture discrimination, age-related bone loss and applicability of the WHO criteria. Osteoporos Int 1999; 10(6):44|-449. 46. Gerdhem P, et al. Ultrasound of the phalanges is not related to a previous fracture.A comparison between ultrasound of the phalanges, calcaneus, and DXA of the spine and hip in 75-year-old women.J Clin Densitom 2002;5(2):159-166.

47. Gluer CC, et al. Osteoporosis: association of recent fractures with quantitative US findings. Radiology 1996;199(3):725-732.
48. Gluer CC, et al.Association of five quantitative ultrasound devices and bone densitometry with osteoporotic vertebral fractures in a populationbased sample: the OPUS Study.J Bone Miner Res 2004;19(5):782-793. 49. Gnudi S, Gualtieri G, Malavolta N. Simultaneous densitometry and quantitative bone sonography in the estimation of osteoporotic fracture risk. Br J Radiol 1998;7 (846):625-629.

50. Gnudi S, Ripamonti C. Quantitative ultrasound at the phalanxes discriminates osteoporotic women with vertebral but not with hip fracture. Ultrasound Med Biol 2004;30(3):357-36I.

5I. Gonnelli S, et al. Diagnostic value of ultrasound analysis and bone densitometry as predictors of vertebral deformity in postmenopausal women. Osteoporos Int 1995;5(6):413-4I8.

52. Gonnelli S, et al. Quantitative ultrasound and dual-energy X-ray absorptiometry in the prediction of fragility fracture in men. Osteoporos Int 2005; 16(8):963-968.

53. Greenspan SL, et al. Precision and discriminatory ability of calcaneal bone assessment technologies. J Bone Miner Res 1997; I2(8): 1303-1313.

54. Greenspan SL, et al. Clinical performance of a highly portable, scanning calcaneal ultrasonometer. Osteoporos Int 2001;12(5):391-398.

55. Guglielmi G, et al. Palangeal quantitative ultrasound, phalangeal morphometric variables, and vertebral fracture discrimination. Calcif Tissue Int 2003;72(4):469-477.

56. Hadji P, et al. Quantitative ultrasound of the os calcis in postmenopausal women with spine and hip fracture.J Clin Densitom 2000;3(3):233-239.

57. Hamanaka Y, et al. Comparison of bone mineral density at various skeletal sites with quantitative ultrasound parameters of the calcaneus for assessment of vertebral fractures.J Bone Miner Metab 1999;17(3):195-200. 58. Hans $D$, et al. Does combining the results from multiple bone sites measured by a new quantitative ultrasound device improve discrimination of hip fracture? J Bone Miner Res 1999;14(4):644-65I.

59. Hans $D$, et al. Is time since hip fracture influencing the discrimination between fractured and nonfractured subjects as assessed at the calcaneum by three technologically different quantitative ultrasound devices? Calcif Tissue Int 2002;7I(6):485-492.

60. Hans D, et al. Hip fracture discrimination study: QUS of the radius and the calcaneum. J Clin Densitom 2003;6(2): 163-I72.

6I. Hartl F, et al. Discriminatory ability of quantitative ultrasound parameters and bone mineral density in a population-based sample of postmenopausal women with vertebral fractures: results of the Basel Osteoporosis Study.J Bone Miner Res 2002;17(2):321-330.

62. He YQ, et al.Assessment of a new quantitative ultrasound calcaneus measurement: precision and discrimination of hip fractures in elderly women compared with dual X-ray absorptiometry. Osteoporos Int 2000; I I (4):354-360.

63. Hernandez JL, et al. Discriminative capacity of calcaneal quantitative ultrasound and of osteoporosis and fracture risk factors in postmenopausal women with osteoporotic fractures. Calcif Tissue Int 2004;74(4):357-365.

64 . Hollevoet $\mathrm{N}$, et al. Tibial ultrasound velocity in women with wrist fracture.J Clin Densitom 2004;7(3):302-306.

65. Ingle BM, Eastell R. Site-specific bone measurements in patients with ankle fracture. Osteoporos Int 2002;13(4):342-347.

66. Karlsson MK, et al.Age, gender, and fragility fractures are associated with differences in quantitative ultrasound independent of bone mineral density. Bone 200I;28(I):II8-I22.

67. Knapp KM, et al. Multisite quantitative ultrasound: Colles' fracture discrimination in postmenopausal women. Osteoporos Int 2002; 13(6):474-479.

68. Knapp KM, et al. Multisite quantitative ultrasound: precision, ageand menopause-related changes, fracture discrimination, and T-score equivalence with dual-energy $\mathrm{X}$-ray absorptiometry. Osteoporos Int 200I;I (2(6):456-464. 
69. Krieg, M.A., et al., Comparison of three bone ultrasounds for the discrimination of subjects with and without osteoporotic fractures among 7562 elderly women.J Bone Miner Res 2003;18(7): I26I-I 266. 70. Kung AW, et al. Quantitative ultrasound and symptomatic vertebral fracture risk in Chinese women. Osteoporos Int 1999; 10(6):456-46I. 71. Lopez-Rodriguez F, et al. Performance of quantitative ultrasound in the discrimination of prevalent osteoporotic fractures in a bone metabolic unit. Bone 2003;32(5):57I-578.

72. Maggi S, et al. Quantitative heel ultrasound in a population-based study in Italy and its relationship with fracture history: the ESOPO study. Osteoporos Int 2006; 17(2):237-244.

73. Matsushita R, et al. Comparison of various biochemical measurements with bone mineral densitometry and quantitative ultrasound for the assessment of vertebral fracture.J Bone Miner Metab 2000;18(3):I58-164. 74. Meszaros $\mathrm{S}$, et al. Calcaneous quantitative ultrasound measurements predicts vertebral fractures in idiopathic male osteoporosis. Joint Bone Spine, 2006.

75. Mikhail MB, Flaster E,Aloia JF. Stiffness in discrimination of patients with vertebral fractures. Osteoporos Int 1999;9(I):24-28.

76. Mulleman D, et al. Quantitative ultrasound of bone in male osteoporosis. Osteoporos Int 2002;13(5):388-393.

77. Muraki S, Yamamoto S, Kanai H. Ultrasound velocity in the tibia in Japanese patients with hip fracture.J Orthop Sci 2002;7(6):623-628. 78. Nguyen TV, Center JR, Eisman JA. Bone mineral density-independent association of quantitative ultrasound measurements and fracture risk in women. Osteoporos Int 2004; I5(I2):942-947.

79. Njeh CF, et al. Comparison of six calcaneal quantitative ultrasound devices: precision and hip fracture discrimination. Osteoporos Int 2000; I ( I2): 105I-1062.

80. Ohishi T, et al. Ultrasound measurement using CUBA clinical system can discriminate between women with and without vertebral fractures. Contact Ultrasound Bone Analyzer.J Clin Densitom 2000;3(3):227-23I. 8I. Peretz A, et al. Evaluation of quantitative ultrasound and dual X-Ray absorptiometry measurements in women with and without fractures.J Clin Densitom 1999;2(2):127-133.

82. Pinheiro MM, et al. Discriminatory ability of quantitative ultrasound measurements is similar to dual-energy $\mathrm{X}$-ray absorptiometry in a Brazilian women population with osteoporotic fracture. Calcif Tissue Int 2003;73(6):555-564.

83. Pluskiewicz W, Drozdzowska B. Ultrasound measurements at the calcaneus in men: differences between healthy and fractured persons and the influence of age and anthropometric features on ultrasound parameters. Osteoporos Int 1999;10(1):47-51.

84. Ross P, et al. Predicting vertebral deformity using bone densitometry at various skeletal sites and calcaneus ultrasound. Bone 1995; 16(3):325-332. 85. Roux C, et al. Ultrasonic backscatter and transmission parameters at the os calcis in postmenopausal osteoporosis.J Bone Miner Res 2001;16(7):1353-1362.

86. Sakata S, et al. Ultrasound bone densitometry of os calcis in elderly Japanese women with hip fracture. Calcif Tissue Int 1997;60(I):2-7.

87. Schneider J, et al. Discrimination of patients with and without vertebral fractures as measured by ultrasound and DXA osteodensitometry. Calcif Tissue Int 2004;74(3):246-254.

88. Schott AM, et al. Ultrasound discriminates patients with hip fracture equally well as dual energy $X$-ray absorptiometry and independently of bone mineral density.J Bone Miner Res 1995; 10(2):243-249.

89. Stegman MR, Heaney RP, Recker RR. Comparison of speed of sound ultrasound with single photon absorptiometry for determining fracture odds ratios.J Bone Miner Res 1995; I0(3):346-352.

90. Travers-Gustafson D, et al. Ultrasound, densitometry, and extraskeletal appendicular fracture risk factors: a cross-sectional report on the Saunders County Bone Quality Study. Calcif Tissue Int 1995;57(4): 267-27I.
91. Stewart $A$, et al.Vertebral fractures in men and women: how discriminative are bone mass measurements? $\mathrm{Br}$ J Radiol 1995;68(8I0):614-620.

92. Turner $\mathrm{CH}$, et al. Calcaneal ultrasonic measurements discriminate hip fracture independently of bone mass. Osteoporos Int 1995;5(2): I30-I 35. 93. Varenna M, et al.Association of quantitative heel ultrasound with history of osteoporotic fractures in elderly men: the ESOPO study. Osteoporos Int 2005; 16(12): 1749-1754.

94. Weiss $\mathrm{M}$, et al. Discrimination of proximal hip fracture by quantitative ultrasound measurement at the radius. Osteoporos Int 2000; I (5): $4|I-4| 6$.

95. Welch A, et al. Broadband ultrasound attenuation (BUA) of the heel bone and its correlates in men and women in the EPIC-Norfolk cohort: a cross-sectional population-based study. Osteoporos Int 2004;15(3):

217-25.

96. Wuster C, et al. Phalangeal osteosonogrammetry study: age-related changes, diagnostic sensitivity, and discrimination power.The Phalangeal Osteosonogrammetry Study Group. J Bone Miner Res 2000; I5(8): |603-1614.

97. Marshall D, Johnell O,Wedel H. Meta-analysis of how well measures of bone mineral density predict occurrence of osteoporotic fractures. Bmj 1996;312(704I):I254-I259.

98. Durosier C, et al. Prediction and discrimination of osteoporotic hip fracture in postmenopausal women.J Clin Densitom 2006;9(4):475-495. 99. Bauer RL. Ethnic differences in hip fracture: a reduced incidence in Mexican Americans. Am J Epidemiol 1988; 127(I):I45- 149.

100. Bauer RL, Deyo RA. Low risk of vertebral fracture in Mexican American women. Arch Intern Med 1987; 147(8): 1437-I439. I0I. Frost ML, Blake GM, Fogelman I. Can the WHO criteria for diagnosing osteoporosis be applied to calcaneal quantitative ultrasound? Osteoporos Int 2000; II (4):32I-330.

102. Faulkner KG, E. von Stetten, Miller P. Discordance in patient classification using T-scores.J Clin Densitom 1999;2(3):343-350. 103. Damilakis J, Perisinakis K, Gourtsoyiannis N. Imaging ultrasonometry of the calcaneus: optimum T-score thresholds for the identification of osteoporotic subjects. Calcif Tissue Int 200 I;68(4):219-224.

104. Knapp KM, et al. Can the WHO definition of osteoporosis be applied to multi-site axial transmission quantitative ultrasound? Osteoporos Int 2004;15(5):367-374.

105. Hans D, et al. Reference data in a Swiss population. Discordance in patient classification using T-scores among calcaneum, spine, and femur.J Clin Densitom 200 I;4(4):29I-298.

106. Hans D, Hartl F, Krieg MA. Device-specific weighted T-score for two quantitative ultrasounds: operational propositions for the management of osteoporosis for 65 years and older women in Switzerland. Osteoporos Int 2003;| 1(3):25I-258.

107. Clowes JA, Peel NF, Eastell R. Device-specific thresholds to diagnose osteoporosis at the proximal femur: an approach to interpreting peripheral bone measurements in clinical practice. Osteoporos Int 2006; I7(9):1293-1302.

108. Black DM, Fordham JN, McCrea JD, Ryan PJ, and the NOS Bone Densitometry Forum and the NOS Scien tific Advisory Group, Position statement on the use of peripheral $\mathrm{x}$-ray absorptiometry in the management of osteoporosis, ed. N.O. Society, 2004.

109. Black DM, Chinn D, Steel S, Patel R, Panayiotou E, Thorpe J, Fordham J. The revised NOS position statement on peripheral x-ray absorptiometry: a listing of device specific T-score thresholds for the clinical interpretation of pDXA examinations, ed. N.O. Society, 2007.

I I0. Siffert RS. Kaufman, J.J., Ultrasonic bone assessment: "The time has come". Bone 2007;40:5-8.

III. Roux C, et al. Broadband ultrasound attenuation imaging: a new imaging method in osteoporosis. J Bone Miner Res 1996; I (8): I I I - I I I8. 
1 12. Hans D, et al. Do ultrasound measurements on the os calcis reflect more the bone microarchitecture than the bone mass?: a two-dimensional histomorphometric study. Bone 1995; 16(3):295-300.

I 13. Krieg MA, et al. [Evaluation of bones using quantitative ultrasonography]. Schweiz Med Wochenschr 1996; I26(5):I59-163. I I4. Seeman, E. and P.D. Delmas, Bone quality--the material and structural basis of bone strength and fragility. N Engl J Med 2006;354(2I):2250-26I. II5. Bouxsein ML. Mechanisms of osteoporosis therapy: a bone strength perspective. Clin Cornerstone 2003;(Suppl 2):SI3-S2I.

I 16. Ammann P, Rizzoli R. Bone strength and its determinants. Osteoporos Int 2003; I4(suppl 3):SI3-SI8.

I 17. Hans D, et al. Ultrasound velocity of trabecular cubes reflects mainly bone density and elasticity. Calcif Tissue Int 1999;64(I): I8-23.

I 18. Hans D, Fuerst T, Uffmann T. Bone density and quality measurement using ultrasound. Curr Opin Rheumatol 1996;8(4):370-375.

1 19. Gluer CC. Quantitative Ultrasound--it is time to focus research efforts. Bone 2007;40(I):9-13.

120. Gluer CC,Wu CY, Genant HK. Broadband ultrasound attenuation signals depend on trabecular orientation: an in vitro study. Osteoporos Int 1993;3(4):185-191.

I2I. Gluer CC, et al. Three quantitative ultrasound parameters reflect bone structure. Calcif Tissue Int 1994;55(I):46-52.

122. Bouxsein ML, Coan BS, Lee SC. Prediction of the strength of the elderly proximal femur by bone mineral density and quantitative ultrasound measurements of the heel and tibia. Bone 1999;25(I):49-54.

123. Bouxsein ML, and S.E. Radloff, Quantitative ultrasound of the calcaneus reflects the mechanical properties of calcaneal trabecular bone. J Bone Miner Res 1997;12(5):839-846.

124. Cheng XG, et al. Prediction of vertebral strength in vitro by spinal bone densitometry and calcaneal ultrasound.J Bone Miner Res 1997;12(10): 172I- 1728.

125. Lochmuller EM, et al. Mechanical strength of the thoracolumbar spine in the elderly: prediction from in situ dual-energy $\mathrm{X}$-ray absorptiometry, quantitative computed tomography (QCT), upper and lower limb peripheral QCT, and quantitative ultrasound. Bone 2002;3I (I):77-84.

126. Lochmuller EM, et al. Radius bone strength in bending, compression, and falling and its correlation with clinical densitometry at multiple sites. J Bone Miner Res 2002;17(9):1629-1638.

127. Hakulinen MA, et al.Ability of ultrasound backscattering to predict mechanical properties of bovine trabecular bone. Ultrasound Med Biol 2004;30(7):919-27.

128. Han S, et al.The ability of quantitative ultrasound to predict the mechanical properties of trabecular bone under different strain rates. Med Eng Phys 1997; 19(8):742-747.

129. Njeh CF, et al. Prediction of human femoral bone strength using ultrasound velocity and BMD: an in vitro study. Osteoporos Int 1997;7(5):47|-477.

130. Durosier C, et al. Combining clinical factors and QUS improves the detection of women both at low and high risk for hip fracture. [submitted].

131. Kanis JA, et al. The use of clinical risk factors enhances the performance of BMD in the prediction of hip and osteoporotic fractures in men and women. Osteoporos Int, 2007.

132. Dargent-Molina P, Piault S, Breart G.A triage strategy based on clinical risk factors for selecting elderly women for treatment or bone densitometry: the EPIDOS prospective study. Osteoporos Int 2005;16(8):898-906.

133. Schott AM, et al. Should age influence the choice of quantitative bone assessment technique in elderly women? The EPIDOS study. Osteoporos Int 2004;15(3): 196-203.

134. De Laet C, et al. Body mass index as a predictor of fracture risk: a meta-analysis. Osteoporos Int 2005; I6(I I):I330-1338.
135. Durosier C, et al. Combining clinical factors and QUS improves both the detection of women at low and high risk of hip fracture. Osteoporos Int 2007;submitted.

136. Kanis JA, et al.A meta-analysis of previous fracture and subsequent fracture risk. Bone 2004;35(2):375-382.

137. Kanis JA, et al.A family history of fracture and fracture risk: a metaanalysis. Bone 2004;35(5): 1029-1037.

138. Kanis JA, et al. Smoking and fracture risk: a meta-analysis. Osteoporos Int 2005; 16(2):155-162.

139. Kanis JA, et al.A meta-analysis of prior corticosteroid use and fracture risk.J Bone Miner Res 2004;19(6):893-899.

140. Dargent-Molina P, et al. Fall-related factors and risk of hip fracture: the EPIDOS prospective study. Lancet 1996;348(902I): 145-149.

14I. Black DM, et al.An assessment tool for predicting fracture risk in postmenopausal women. Osteoporos Int 2001;12(7):519-528.

142. Hans D, et al. 10 year probability of osteoporotic hip fracture in I 2958 elderly women combining clinical factors and hell bone ultrasound: The combined "SEMOF+EPIDOS" prospective cohorts.J Bone Miner Res 2008 , in press.

I43. Haiat $\mathrm{G}$, et al.Variation of ultrasonic parameters with microstructure and material properties of trabecular bone: a 3D model simulation.J Bone Miner Res 2007;22(5):665-674.

144. Sakata S, et al.Assessing bone status beyond BMD: evaluation of bone geometry and porosity by quantitative ultrasound of human finger phalanges. J Bone Miner Res 2004;19(6):924-930.

145. Barkmann R, et al.Assessment of the geometry of human finger phalanges using quantitative ultrasound in vivo. Osteoporos Int 2000; II (9):745-755

I46. Lee SC, Coan BS, Bouxsein ML.Tibial ultrasound velocity measured in situ predicts the material properties of tibial cortical bone. Bone 1997;2I(I): I I9-125.

147. Muller ME,Webber CE, Bouxsein ML. Predicting the failure load of the distal radius. Osteoporos Int 2003; I4(4):345-352.

I48. Naessen T, Mallmin H, Ljunghall S. Heel ultrasound in women after long-term ERT compared with bone densities in the forearm, spine and hip. Osteoporos Int 1995;5(3):205-210.

149. Gonnelli S, et al.Alendronate treatment in men with primary osteoporosis: a three-year longitudinal study. Calcif Tissue Int 2003;73(2):133-139.

150. Gonnelli S, et al. Heel ultrasonography in monitoring alendronate therapy: a four-year longitudinal study. Osteoporos Int 2002;13(5):415-42।. 15I. Gonnelli S, et al. Ultrasound parameters in osteoporotic patients treated with salmon calcitonin: a longitudinal study. Osteoporos Int 1996;6(4):303-307.

152. Gonnelli S, et al.Teriparatide's effects on quantitative ultrasound parameters and bone density in women with established osteoporosis. Osteoporos Int 2006;17(10):I524-1531.

153. Krieg MA, et al. Effect of supplementation with vitamin D3 and calcium on quantitative ultrasound of bone in elderly institutionalized women: a longitudinal study. Osteoporos Int 1999;9(6):483-488. 154. Sahota O, et al.A comparison of the longitudinal changes in quantitative ultrasound with dual-energy $\mathrm{X}$-ray absorptiometry: the four-year effects of hormone replacement therapy. Osteoporos Int 2000; II (I):52-58.

155. Hadji P, et al.Assessment by quantitative ultrasonometry of the effects of hormone replacement therapy on bone mass. Am J Obstet Gynecol 2000;182(3):529-534.

156. Balikian P, et al. Bone mineral density and broadband ultrasound attenuation with estrogen treatment of postmenopausal women.J Clin Densitom 1998; I(I):19-26. 
157. Frost ML, Blake GM, Fogelman. Changes in QUS and BMD measurements with antiresorptive therapy: a two-year longitudinal study. Calcif Tissue Int 200I;69(3):I38-146.

158. Moschonis G, Manios Y. Skeletal site-dependent response of bone mineral density and quantitative ultrasound parameters following a I2-month dietary intervention using dairy products fortified with calcium and vitamin D: the Postmenopausal Health Study. Br J Nutr 2006;96(6): I I40-II I48.

159. De Aloysio $D$, et al. Bone effects of transdermal hormone replacement therapy in postmenopausal women as evaluated by means of ultrasound: an open one-year prospective study. Maturitas 1997;27(I): 6I-68.

160. Mauloni M, et al. Monitoring bone effect of transdermal hormone replacement therapy by ultrasound investigation at the phalanx: a fouryear follow-up study. Menopause 2000;7(6):402-4I2.

161. Zitzmann M, et al. Monitoring bone density in hypogonadal men by quantitative phalangeal ultrasound. Bone 2002;31(3):422-429.

162. Seriolo B, et al. Bone metabolism changes during anti-TNF-alpha therapy in patients with active rheumatoid arthritis. Ann NY Acad Sci 2006; 1069:420-427.

163. Drake WM, et al. Use of phalangeal bone mineral density and multisite speed of sound conduction to monitor therapy with alendronate in postmenopausal women. Osteoporos Int 2002;13(3):249-256.

164. Knapp KM, et al.An investigation of unique and shared gene effects on speed of sound and bone density using axial transmission quantitative ultrasound and DXA in twins. J Bone Miner Res 2003; |8(8):1525-1530. 165. Fuerst T, Njeh CF, Hans D. Quality assurance and quality control in quantitative ultrasound, in Quantitative ultrasound: Assessment of osteoporosis and bone status, CF Njeh, et al., eds. 1999, Martin Dunitz: London:163-175.

166.A Dictionary of Epidemiology. $3^{\text {rd }}$, ed. J.M. Last. 1995, New York: Oxford University Press.

167. Chappard C, et al. Ultrasound measurement on the calcaneus: influence of immersion time and rotation of the foot. Osteoporos Int 1999;9(4):318-326.
168. Cheng $S$, et al. Influence of region of interest and bone size on calcaneal BMD: implications for the accuracy of quantitative ultrasound assessments at the calcaneus. Br J Radiol 2002;75(889):59-68.

169. Hans D, et al. Influence of anthropometric parameters on ultrasound measurements of Os calcis. Osteoporos Int 1995;5(5):371-376.

170. Barkmann R, Gluer C. Error sources in quantitative ultrasound measurement, in Quantitative ultrasound:Assessment of osteoporosis and bone status, C.F. Njeh, et al., eds. 1999, Martin Dunitz: London:I0I-107.

171. Kotzki PO, et al. Influence of fat on ultrasound measurements of the os calcis. Calcif Tissue Int 1994:54(2):91-95.

172. Chappard C, et al. Evaluation of error bounds on calcaneal speed of sound caused by surrounding soft tissue.J Clin Densitom 2000;3(2): |2|-|3|.

173. Johansen A, Stone MD. The effect of ankle oedema on bone ultrasound assessment at the heel. Osteoporos Int 1997;7(I):44-47.

174. Ikeda Y, Iki M. Precision control and seasonal variations in quantitative ultrasound measurement of the calcaneus.J Bone Miner Metab 2004;22(6):588-593.

175. Evans WD, Jones EA, Owen GM. Factors affecting the in vivo precision of broad-band ultrasonic attenuation. Phys Med Biol 1995;40(I):|37-|5I.

176. Paggiosi MA, et al. Effect of temperature on the longitudinal variability of quantitative ultrasound variables. J Clin Densitom 2005;8(4):436-444. 177. Hans $D$, et al. Longitudinal quality control methodology for the quantitative ultrasound Achilles+ in clinical trial settings. Osteoporos Int 2002; |3(10):788-795.

178. Njeh CF, et al. Factors influencing the speed of sound through the proximal phalanges. J Clin Densitom 1999;2(3):24I-249.

179. Laugier P, Giat P, Berger G. Broadband ultrasonic attenuation imaging: a new imaging technique of the os calcis. Calcif Tissue Int 1994;54(2): 83-86. 